\title{
F-response behaviour in a control population
}

\author{
S PEIOGLOU-HARMOUSSI, ${ }^{*}$ D HOWEL,$\uparrow$ PRW FA WCETT, ${ }^{*}$ DD BARWICK \\ From the Department of Clinical Neurophysiology, ${ }^{*}$ Regional Centre, Newcastle General Hospital, and the \\ Department of Medical Statistics, $\uparrow$ University of Newcastle upon Tyne, UK
}

SUMMARY Various parameters of the F-response including minimal and maximal latency, chronodispersion, amplitude (absolute and $\mathrm{F} \% \mathrm{M}$ ) and duration have been determined for a sample of 20 responses in the median and ulnar nerves bilaterally in normal healthy subjects of both sexes aged between 12 to 81 years. Side to side comparisons revealed no significant differences in any of the parameters except for slightly longer minimum $\mathrm{F}$ latencies in the right median nerve. Strong correlations were found between minimal and maximal $F$ latencies and height, while much weaker relationships were found between these parameters and age. There was a slight but significant relationship between $\mathrm{F} \% \mathrm{M}$ and age, but no age or sex related changes were noted for any of the remaining F-response parameters.

Over recent years the value of F-responses in the investigation of patients with both generalised and localised disturbances in peripheral nerves has become well established. ${ }^{1-5}$ The majority of reports have concentrated on the measurement of F-response latency, which has proved to be a more sensitive indicator of a conduction abnormality than the maximal motor and sensory conduction velocities. ${ }^{6}$ In particular the F-response has been helpful in the examination of proximally situated lesions which are inaccessible to conventional techniques. ${ }^{78}$

Less attention, however, has been paid to other aspects of the F-response, including amplitude, duration, shape and frequency. Since the composition and discharge characteristics of motor unit potentials, which are the basic components of these late responses, may be altered by pathology, examination of these parameters might provide useful information about the presence and nature of a disorder affecting the upper and lower motor neurons.

In the present study we have examined F-response latency, amplitude and duration in the median and ulnar nerves of healthy subjects of both sexes and different ages. In order to be able to

Present address Dr S Harmoussi PhD, B. Department of Neurology, General Hospital, Saint Dimitrios, Salonika, Greece.

Address for reprint requests: PRW Fawcett, Department of Clinical Neurophysiology, Regional Neurological Centre, Newcastle General Hospital, Westgate Road, Newcastle upon Tyne, NE4 6BE, UK.

Received 6 November 1984 and in revised form 27 March 1985. Accepted 5 April 1985 examine side to side differences in pathological situations, observations were made on both upper limbs. As a necessary precursor to F-response measurement, conventional motor conduction studies were also performed in each nerve. F-response frequency and shape were studied in a separate investigation, the findings of which are presented elsewhere. ${ }^{9}$

\section{Subjects and methods}

The control population consisted of 64 normal healthy subjects drawn mainly from medical and nursing staff and university students; equal numbers of men and women took part. Their ages ranged from 12 to 81 , the majority being between 20 and 60 years old (mean 43.0, SD 16.5). All but two were right handed. There were at least 12 subjects in each of the age groups 12-30, 31-40, 41-50, 51-60 and 61-81 (6 of each sex). Informed consent was obtained from each subject.

The investigations were carried out in a warm room and care was taken to ensure that the subject was relaxed. The skin temperature of the hand was monitored with a thermistor (Light Laboratories, Brighton, Sussex) and maintained at about $34^{\circ} \mathrm{C}$ with a heating lamp. A DISA 1500 EMG Digital system was used to carry out all studies. Stimulation was performed using surface pad electrodes soaked in saline (Disa 13L 22) with the cathode situated distally. Recordings of the compound muscle action potential were made using saline soaked pads of $1 \mathrm{~cm}$ diameter connected to metal disc electrodes mounted in a plastic frame. The active electrode was placed over the muscle belly and the reference electrode was positioned over the tendon at the base of the appropriate first metacarpal. A stimulus frequency of $1 \mathrm{~Hz}$ and pulse duration of $0.2 \mathrm{~ms}$ were used. Recordings were made from the thenar and 
hypothenar muscles for the median and ulnar nerves respectively. Gain settings of $0.5 \mathrm{mV}$ and $5 \mathrm{mV}$ were used for measuring the latency and amplitude respectively. The terminal latency, peak to peak M-response amplitude and motor conduction velocity in the forearm and arm segments were determined in both nerves.

\section{F-response studies}

The F-response in median and ulnar nerves were recorded from the abductor pollicis brevis and abductor digiti minimi muscles respectively using the same electrode arrangement as for conduction velocity studies. Each nerve was stimulated supramaximally with stimulus frequency 1 $\mathrm{Hz}$ pulse duration of $0.2 \mathrm{~ms}$, and recordings were made with a sweep-speed of $5 \mathrm{~ms} / \mathrm{cm}$ and sensitivity of 0.2 or 0.5 $\mathrm{mV}$ per division. The F-responses were clearly isolated from the simultaneously recorded $M$-response, and in order to differentiate them from background noise, only those deflections which showed a clear deviation from the baseline and an amplitude of $40 \mu \mathrm{V}$ or more were accepted. Successive stimuli were applied until a total of 20 F-responses were recorded. The latency of the F-response was taken as the interval between stimulus artifact and first deflection of the late evoked response. The minimum and maximum latency values were determined for each nerve, and F-chronodispersion was defined as the difference between these two values. F-response duration was measured between the onset of the deflection from the base line and the final return to the base line. The peak to peak amplitude of each F-response was measured, and in addition to the absolute value it was also expressed as a percentage of the corresponding M-response (F\%M Amplitude). Permanent recordings were made on Polaroid film.

The possible recurrence of identical F-responses was examined on the basis of latency and configuration. Successive stimuli were applied until a total of $20 \mathrm{~F}$-responses were recorded.

\section{Statistical methods}

Non parametric statistical tests were used to compare sex groups (Mann Whitney test) and right and left sides (Wilcoxon signed rank test) as some variables have a nonGaussian distribution; rank correlation coefficients were calculated for the same reason. The $1 \%$ significance level was used to guard against spurious significant results which may occur when so many variables are tested simultaneously. Techniques assuming a Gaussian distribution ( $t$ test, analysis of covariance, linear regression) were used on latencies alone.
Results

\section{Conduction studies}

The data for motor terminal latency, conduction velocity and M-response amplitude are summarised for each nerve in table 1 .

Over the age range studied there was no consistent correlation between age and distal motor latency or motor conduction velocity in the distal segment. A trend towards reduction in proximal velocity with increasing age was noted, but this did not reach statistical significance. There was no difference in conduction velocity between sexes, but a highly significant increase $(p<0.0001)$ in conduction velocity was found from distal to proximal segments, which was of the order of $11 \mathrm{~m} / \mathrm{s}$.

The amplitude of the evoked muscle action potential was significantly higher in the right median nerve than the left $(p<0.01)$, and although a similar difference was observed in the ulnar nerve, this did not reach statistical significance. Because of these differences the values from the two sides were not pooled.

\section{F-response studies}

Satisfactory recordings of late responses were obtained in each nerve in all of the subjects. Typical recordings from two subjects are presented in the figure, showing the variation in latency, amplitude and configuration with successive sweeps which is characteristic of the F-response.

\section{F-minimum and maximum latencies}

Values for the minimum and maximum F-response latencies in each of the four nerves studied are presented in table 2. For each control subject, age, sex and height were recorded and each of these factors was tested for a possible influence on the F-latencies. These three factors are not independent. The two sex groups were well balanced for age but males were significantly taller than females $(t=3.2, \mathrm{df}=58, \mathrm{p}<0.01)$. There was also a tendency for the older subjects to be shorter $(r=$ $-0.28, p<0.05)$. An analysis of covariance showed

Table 1 Motor nerve conduction data in controls

\begin{tabular}{|c|c|c|c|c|c|c|c|c|c|}
\hline & \multirow{2}{*}{$\begin{array}{l}\text { Termin } \\
\text { latency } \\
\text { (ms) } \\
\text { Mean }\end{array}$} & \multirow{2}{*}{$S D$} & \multicolumn{4}{|c|}{$\begin{array}{l}\text { Conduction velocitiy } \\
(\mathrm{m} / \mathrm{s})\end{array}$} & \multicolumn{2}{|c|}{$\begin{array}{l}\text { M-response } \\
\text { amplitude }\end{array}$} & \multirow[t]{2}{*}{$\begin{array}{l}\text { Number } \\
\text { of cases }\end{array}$} \\
\hline & & & $\begin{array}{l}\text { Distal* } \\
\text { Mean }\end{array}$ & $S D$ & $\begin{array}{l}\text { Proximal } \\
\text { Mean }\end{array}$ & $S D$ & Mean & $S D$ & \\
\hline $\begin{array}{l}\text { Right median } \\
\text { Left median } \\
\text { Right ulnar } \\
\text { Left ulnar }\end{array}$ & $\begin{array}{l}3 \cdot 5 \\
3 \cdot 4 \\
2 \cdot 7 \\
2 \cdot 6\end{array}$ & $\begin{array}{l}0.35 \\
0.36 \\
0.32 \\
0.29\end{array}$ & $\begin{array}{l}58 \\
59 \\
57 \\
57\end{array}$ & $\begin{array}{l}4 \cdot 5 \\
4 \cdot 8 \\
5 \cdot 1 \\
5 \cdot 1\end{array}$ & $\begin{array}{l}69 \\
68 \\
68 \\
68\end{array}$ & $\begin{array}{l}6 \cdot 5 \\
7 \cdot 2 \\
6 \cdot 8 \\
6 \cdot 5\end{array}$ & $\begin{array}{l}15 \cdot 5 \dagger \\
14 \cdot 2 \dagger \\
12 \cdot 0 \\
10.8\end{array}$ & $\begin{array}{l}4 \cdot 5 \\
4 \cdot 1 \\
4 \cdot 1 \\
3 \cdot 5\end{array}$ & $\begin{array}{l}58 \\
62 \\
64 \\
64\end{array}$ \\
\hline
\end{tabular}

*All proximal velocities significantly greater than distal velocities $(p<0.001)$.

†M-response amplitudes has significant right/left difference in median nerve $(p<0.01)$. 
Table 2 Summary of F-response latencies in controls

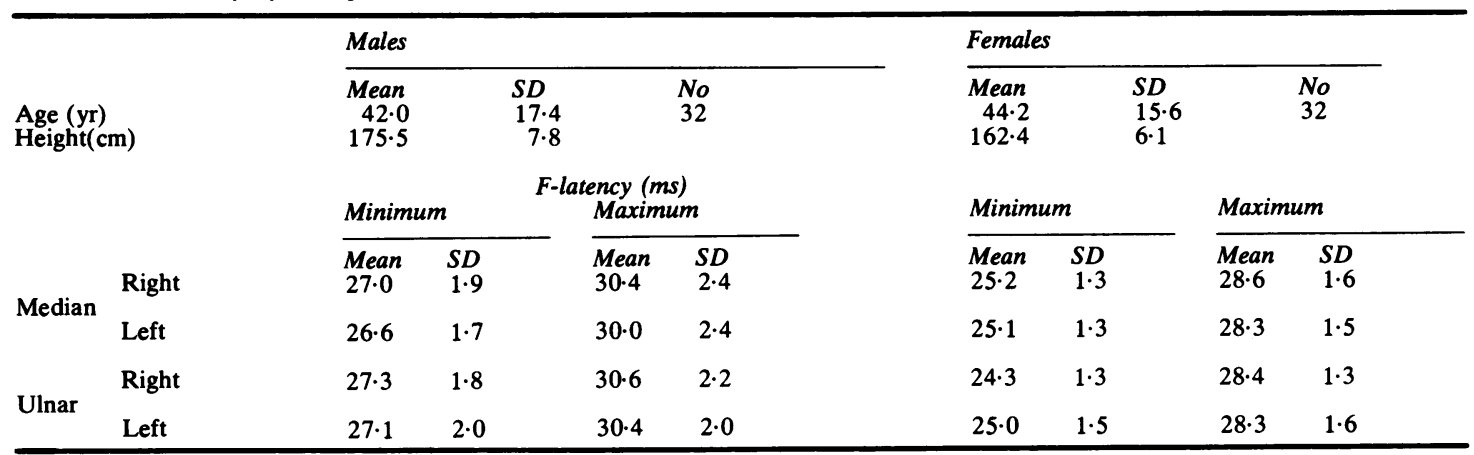

that the significant difference between the sexes for maximum and minimum F-latencies $(p<0.01)$ can be explained by the difference in height between the two groups. Comparison of the right and left sides revealed a significant difference in only the minimum latency values of the median nerve, the right side being on average $0.3 \mathrm{~ms}$ longer $(\mathrm{p}<$
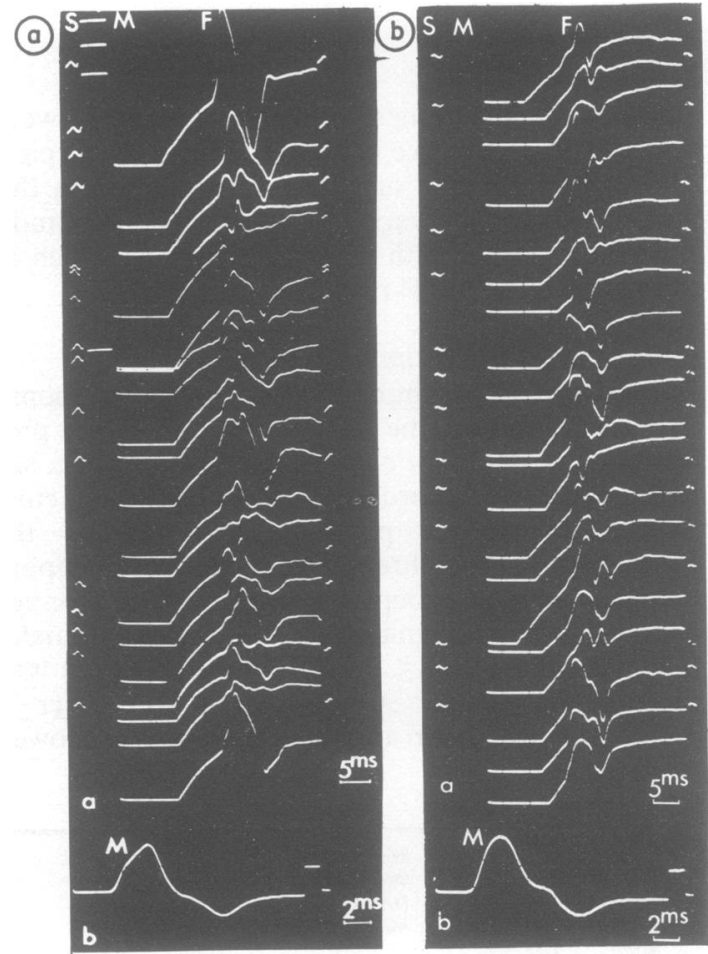

Fig Recordings of 20 consecutive F-responses in two control subjects; (a) 36 years old male: (b) 41 years old female. Note the typical variation in latency, amplitude and configuration of the F-responses. $S=$ Stimulus; $M=$ Direct $M$-response; $F=F$-response. Gain calibration (a) $0.2 \mathrm{mV}$; (b) $5.0 \mathrm{mV}$.
$0 \cdot 001)$. Nevertheless the values from the two sides were not pooled, since side to side comparisons were to be made in the patient group. Calculation of Spearman's rank correlation coefficient showed that the minimum and maximum F-latencies were well correlated with height and to a lesser extent with age (table 3). Because of the relationship of latencies with height and age, a regression equation was derived to allow prediction of the F-latency values from these variables (table 4).

\section{F-chronodispersion}

The difference between minimum and maximum values varied between 1.3 and 8.4 in the four nerves studied with mean values of 3.1 to $3.6 \mathrm{~ms}$ (table 5). There were no significant differences between the values for the right and left sides. There was also no correlation between $\mathrm{F}$-chronodispersion and age, height or sex of the subject.

\section{F-amplitude}

The absolute F-response amplitude values ranged from 40 to $2000 \mu \mathrm{V}$ in the median and 40 to 1500 $\mu \mathrm{V}$ in the ulnar nerves. The distribution of amplitude values tended to be positively skewed and therefore the median rather than mean values were determined for each nerve. Median values varied from 100 to between 625 to $770 \mu \mathrm{V}$ in the four nerves, with median of the median values ranging from 200 to $240 \mu \mathrm{V}$ (table 5). There was no significant side to side difference in absolute F-amplitude for the same nerves and no correlation between this parameter and age or sex. The F-response amplitude was also expressed as a percentage of the M-response (F\%M), and for each nerve the median $\mathrm{F} \% \mathrm{M}$ value was determined. The median $\mathrm{F} \% \mathrm{M}$ values ranged between $0.5 \%$ to $5.9 \%$, while the median of the median values varied between $1.6 \%$ to $2.0 \%$. The $\mathrm{F} \% \mathrm{M}$ amplitude also showed no significant differences between the two sides, but a positive correlation was noted with age. 


\section{F-Duration}

The mean duration of the F-responses in individual control subjects varied between 7.2 and $11.8 \mathrm{~ms}$ for the median nerves and 6.5 and $13.7 \mathrm{~ms}$ in the ulnar nerves, with mean values of $9.4 \mathrm{~ms}$ and $10.1 \mathrm{~ms}$ for both median and both ulnar nerves respectively (table 5). There was no significant difference between the two sides, and no correlation with age or sex. The values tended to be slightly greater in the ulnar nerves, but the difference was not significant.

\section{F-Shape and Identical Responses}

These characteristics of the F-response were not systematically studied in the present investigation. However, as previously reported there was a marked variability in F-response shape in all of the control subjects, without any obvious associations with age or sex (figure, $A$ and $B$ ). Occasionally identical responses were observed in the sample of 20 , but this appeared to be the exception rather than the rule. Both these features of the F-response have been examined in more detail elsewhere.

\section{Discussion}

The purpose of the present study was to investigate the behaviour of various characteristics of the F-response in respect of age and sex, and to establish quantitative data for some of the newer F-response parameters. As side to side comparisons are frequently made in clinical practice, this was also examined for both $\mathrm{F}$-responses and motor conduc-

Table 3 Correlation between F-response latency and (a) Height* (b) Age

\begin{tabular}{|c|c|c|c|c|}
\hline & \multicolumn{2}{|l|}{ Height } & \multicolumn{2}{|l|}{ Age } \\
\hline & $\begin{array}{l}\text { Minimum } \\
\text { latency }\end{array}$ & $\begin{array}{l}\text { Maximum } \\
\text { latency }\end{array}$ & $\begin{array}{l}\text { Minimum } \\
\text { latency }\end{array}$ & $\begin{array}{l}\text { Maximum } \\
\text { latency }\end{array}$ \\
\hline $\begin{array}{l}\text { Right median } \\
\text { Right ulnar } \\
\text { Left median } \\
\text { Left ulnar }\end{array}$ & $\begin{array}{l}0.45 \\
0.56 \\
0.46 \\
0.63\end{array}$ & $\begin{array}{l}0.36 \\
0.60 \\
0.37 \\
0.60\end{array}$ & $\begin{array}{l}0.22 \\
0.24 \\
0.37 \\
0.21\end{array}$ & $\begin{array}{l}0.30 \\
0.23 \\
0.37 \\
0.29\end{array}$ \\
\hline
\end{tabular}

*Spearman's Rank Correlation coefficient significant at $1 \%$ level.

Table 4 Prediction of $F$-response latencies and age

\begin{tabular}{|c|c|c|c|c|c|c|}
\hline & & & \multirow[b]{2}{*}{ Constant } & \multicolumn{2}{|c|}{ Regression coefficient } & \multirow{2}{*}{$\begin{array}{l}95 \% \text { Confidence } \\
\text { interval for prediction }\end{array}$} \\
\hline & & & & Age & Height & \\
\hline \multirow{4}{*}{ Minimum } & \multirow{2}{*}{ Right } & Median & $-2 \cdot 4$ & 0.030 & $0 \cdot 1614$ & \pm 2.4 \\
\hline & & Ulnar & $-3 \cdot 7$ & 0.034 & $0 \cdot 1692$ & $\pm 2 \cdot 2$ \\
\hline & \multirow{2}{*}{ Left } & Median & $1 \cdot 4$ & 0.041 & 0.1343 & $\pm 2 \cdot 4$ \\
\hline & & Ulnar & $-4 \cdot 1$ & 0.030 & 0.1707 & $\pm 2 \cdot 7$ \\
\hline \multirow{4}{*}{ Maximum } & \multirow{2}{*}{ Right } & Median & -0.6 & 0.031 & $0 \cdot 1704$ & \pm 3.4 \\
\hline & & Ulnar & -3.9 & 0.041 & 0.1870 & $\pm 2 \cdot 6$ \\
\hline & \multirow{2}{*}{ Left } & Median & $2 \cdot 1$ & 0.048 & 0.1477 & $\pm 3 \cdot 5$ \\
\hline & & Ulnar & $-2 \cdot 3$ & 0.037 & 0.1777 & $\pm 2 \cdot 7$ \\
\hline
\end{tabular}

Example: Minimum F-latency for right ulnar nerve will be F-latency $(\mathrm{ms})=-3 \cdot 7+(0.034 \times$ age in yr $)+(0.1622 \times$ height in $\mathrm{cm}) \pm 2 \cdot 2$ ( $95 \%$ confidence interval). Mean minimum F-latency values were greater in the right median nerve than the left.

Table 5 Summary of F-response chronodispersion, duration and amplitude data

\begin{tabular}{|c|c|c|c|c|c|c|c|c|c|c|c|}
\hline & \multicolumn{2}{|c|}{$\begin{array}{l}\text { Mean } \\
\text { chronodispersion } \\
\text { (ms) }\end{array}$} & \multicolumn{2}{|c|}{$\begin{array}{l}\text { Mean } \\
\text { duration } \\
\text { (ms) }\end{array}$} & \multicolumn{3}{|c|}{$\begin{array}{l}\text { Median } \\
\text { amplitude } \\
(\mu v)\end{array}$} & \multicolumn{3}{|c|}{$\begin{array}{l}\text { Median } \\
\text { F\%M } \\
\text { amplitude }\end{array}$} & \multirow[t]{2}{*}{$\begin{array}{l}\text { No of } \\
\text { cases }\end{array}$} \\
\hline & Mean & $S D$ & Mean & $S D$ & Min & Med & $\operatorname{Max}$ & Min & Med & $\operatorname{Max}$ & \\
\hline $\begin{array}{l}\text { Right median } \\
\text { Left median } \\
\text { Right ulnar } \\
\text { Left ulnar }\end{array}$ & $\begin{array}{l}3 \cdot 6 \\
3 \cdot 3 \\
3 \cdot 1 \\
3 \cdot 3\end{array}$ & $\begin{array}{l}1 \cdot 2 \\
1 \cdot 3 \\
0 \cdot 7 \\
1 \cdot 1\end{array}$ & $\begin{array}{r}9.4 \\
9.4 \\
10.1 \\
10.2\end{array}$ & $\begin{array}{l}1 \cdot 1 \\
1 \cdot 0 \\
1 \cdot 2 \\
1 \cdot 5\end{array}$ & $\begin{array}{l}100 \\
100 \\
100 \\
100\end{array}$ & $\begin{array}{l}225 \\
240 \\
209 \\
200\end{array}$ & $\begin{array}{l}625 \\
635 \\
650 \\
770\end{array}$ & $\begin{array}{l}0.8 \\
0.5 \\
1.0 \\
0.7\end{array}$ & $\begin{array}{l}1 \cdot 6 \\
1.8 \\
1.8 \\
2 \cdot 0\end{array}$ & $\begin{array}{l}3 \cdot 8 \\
5 \cdot 5 \\
3 \cdot 9 \\
5 \cdot 9\end{array}$ & $\begin{array}{l}57^{*} \\
61 \dagger \\
64 \\
64\end{array}$ \\
\hline
\end{tabular}

* Mean chronodispersion calculations based on 58 cases.

tMean chronodispersion calculations based on 60 cases. 
tion velocities which have a direct bearing on F-response latencies.

The motor conduction velocities in distal and proximal segments of the median and ulnar nerves reported here are in general agreement with the results obtained by previous authors. ${ }^{10-12}$ As in other reports ${ }^{1314}$ there was no significant difference in motor conduction velocity between the two sides in both the median and ulnar nerves. However the compound muscle action potential amplitudes were slightly, and in the case of the median nerve significantly, larger on the right side, reflecting the fact that almost all of controls were right-handed with the probability of greater muscular development on the dominant side. There was no significant change in motor conduction velocity with age in these subjects, but the amplitude of the M-response did tend to decline with increasing age, although this, in contrast to the findings of Campbell et al, ${ }^{16}$ did not reach statistical significance. This agerelated decrease in $\mathbf{M}$ amplitude is thought to reflect an overall reduction in the number of motor units, which becomes particularly pronounced after the age of 60 years. ${ }^{16}$

There can now be little doubt that the F-response represents a recurrent discharge in motor units activated by an antidromic impulse following peripheral nerve stimulation. ${ }^{17-20}$ Furthermore, following the early work of Kimura, ${ }^{1}$ Panayiotopoulous ${ }^{34}$ and others, ${ }^{25}$ the clinical value of measuring the F-response latency as an indication of conduction of motor axons is firmly established. There is however, dispute concerning the use of F-latency for conduction velocity determinations, and certain workers prefer to rely on minimum $F$ latency measurements alone. ${ }^{21}$ Opinions vary with regard to the number of F-responses required to obtain a correct minimum latency value. Lachman $e^{a} a^{\text {s }}$ recorded 10 responses, but Panayiotopoulos et al ${ }^{3}$ showed that in control subjects only one to three of 20 consecutive F-responses were conducted along the fastest motor fibres, and they suggested that at least 20 responses should be measured in order to establish the shortest latency. We have also examined this aspect in a much larger population of F-responses and found that the minimum value of 20 had only a $59 \%$ probability of being within $0.5 \mathrm{~ms}$ and a $76 \%$ probability of being within $1 \mathrm{~ms}$ of the minimum value obtained from at least 100 responses (in preparation). Nevertheless since the collection of a large sample of responses is time consuming and not well tolerated by some patients, a total of 20 was decided to be a satisfactory compromise.

The present study has confirmed the direct relationship between minimum F-response latency and height as reported by others, ${ }^{2}{ }^{22} 23$ and also between maximum F-latency and height, while a much weaker correlation was found with age. Values for the mean minimum F-response latencies irrespective of these variables compare closely with the findings of Lachman et al. ${ }^{5}$ Comparison of the findings in the four nerves examined revealed no significant differences apart from a slightly higher minimal F-latency value in the right median nerve, which may reflect an increased susceptibility to minor trauma in this nerve in the dominant limb, for example at the wrist within the carpal tunnel. Nevertheless slight differences were found between the values for the regression coefficients relating latency, height and age in the four nerves and also between these findings and those of Lachman et al. ${ }^{5}$ These differences are likely to be due in part to the errors imposed on the minimum and maximum latency values in each nerve by the small sample used to obtain the latency value, and also in respect of the two studies the differences in sample size.

Recent reports concerning changes in F-response amplitude in neuropathies and spasticity have highlighted the value of this aspect of the late response. ${ }^{62324}$ The actual amplitude value will be influenced by a variety of factors including the characteristics of the recording electrodes, skin impedence and skinfold thickness, depth of the motor unit within the muscle, relationship of the end plate zone of the motor unit to the active recording electrode, the size of the motor unit and the number of synchronously active motor units giving rise to the surface recorded late response. Because some of these factors may have differing effects in different individual subjects, the F-response amplitude has been expressed as a percentage of the simultaneously recorded maximal M-response as well as the absolute value.

The absolute F-response amplitude tended to show an increase with age, but this did not reach statistical significance. However a significantly positive correlation was found between $\mathrm{F} \% \mathrm{M}$ amplitude and age, reflecting the combination of a downward trend in absolute $\mathrm{M}$-response amplitude and increasing trend in F-response amplitude. This relative increase in $F$ amplitude with age may arise from either an increase in the size of individual motor units or increased synchronisation and/or numbers of motor units making up the F-response. The authors are unaware of any evidence suggesting an increase in central excitability with age, and desynchronisation of the motor unit latencies due to increasing scatter of axonal velocities would be expected. Evidence from other studies which have shown an age related increase in size of motor units ${ }^{25-27}$ would seem to indicate that this is the most likely mechanism. 
The relationship between $\mathrm{F}$ amplitude and latency has been investigated by Yates and Brown ${ }^{28}$ who failed to show any link between the surface voltage and latency in single unit recurrent discharges despite the demonstration of such an association for motor unit potentials recruited to the direct M-response. ${ }^{29}$ It might be expected that larger motor units which have larger axons than smaller motor units ${ }^{30}$ would consequently have shorter latencies. Yates and Brown ${ }^{28}$ proposed that the breakdown in the relationship occurred proximally at the level of the nerve roots or in the central delay for the turnabout time of the nerve impulse. Another explanation in the context of the present study is the variable combinations of different motor units, the summated voltages of which give rise to the overall surface recorded F-response. Yates and Brown ${ }^{28}$ clearly showed that in conditions of supramaximal nerve stimulation as pertained here, there was a much greater chance of two or more motor units producing recurrent discharges.

As with amplitude, the duration of the F-response depends upon a number of factors, the most important of which are the size of the individual motor units, the larger units tending to have longer durations, ${ }^{30}$ and the number of simultaneously active motor units and their relative latencies. The values obtained here compare closely with those reported by Kimura et al $^{30}$ who employed the same criteria for $F$ duration measurement. Other authors who have examined this aspect of the F-response have used different definitions of $F$ duration which are based on either averaged responses, ${ }^{31}$ or interval between the onset of the fastest F-response and the end of the slowest F-response (F-"complex" duration), ${ }^{632}$ and consequently the findings are not comparable. Fisher ${ }^{33}$ found evidence of a negative correlation between $F$ duration and latency from which he concluded that there was an orderly antidromic activation of motor neurons. However we were unable to confirm such a relationship between duration and latency in the present study, nor was there any relationship between duration and age.

The shape of the F-responses varied considerably reflecting the different individual motor units and combinations of motor units activated with each successive stimulus. No attempt was made in the present study to examine systematically this feature of the F-response, although the occurrence of identical responses was noted in a number of recordings. More detailed and quantitative information concerning the shape, frequency of identical responses and overall frequency of F-response production are presented in the accompanying paper. ${ }^{9}$

The measurement of $F$ latency has proved to be a valuable adjunct to conventional motor conduction velocity, and has the considerable virtues of being relatively simple to perform, reliable and reproducible. Other parameters of the late response which have been determined in this study require rather more time and attention. However, our experience with these newer aspects of the F-response in conditions affecting the upper and lower motor neurons has shown them to be worther of study and helpful in the identification of pathology.

Dr S Peioglou-Harmoussi was supported by a Greek State Scholarship Fund (IKY).

\section{References}

' Kimura J. ' $F$ ' wave velocity in the central segment of the median and ulnar nerve. A study in normal subjects and in patients with Charcot-Marie-Tooth disease. Neurology (Minneap) 1974;24:539-46.

${ }^{2}$ Conrad B, Aschoff JP, Fischler M. Der diagnostische Wert der F-Wellen-Latenz. J Neurol 1975;210:1519.

${ }^{3}$ Panayiotopoulos CP, Scarpalezos S, Nastas PE. F-wave studies on the deep peroneal nerve. Part 1: control subjects. J Neurol Sci 1977;31:319-29.

${ }^{4}$ Panayiotopoulos CP, Scarpalezos S. F-wave studies on the deep peroneal nerve. Part 2: 1-chronic renal failure, 2-Limbgirdle muscular dystrophy. J Neurol Sci 1977;31:331-41.

${ }^{5}$ Lachman T, Shahani BT, Young RR. Late responses and aids to diagnosis in peripheral neuropathy. $J$ Neurol Neurosurg Psychiatry 1980;43:156-62.

- Shahani BT, Potts F, Domingue J. F-response studies in Peripheral Neuropathies. Neurology (Minneap) 1980;30:409-10.

7 Shahani BT, Sumner AJ. Electrophysiological studies in peripheral neuropathy: early detection and monitoring. In: Stalberg E, Young RR, eds. Clinical Neurophysiology. London: Butterworths, 1981:11744.

${ }^{8}$ Eisen A, Schomer D, Melmed C. An electrophysiological method for examining lumbosacral root compression. Can J Neurol 1977;4:117-123.

${ }^{9}$ Peioglou-Harmousi S, Fawcett PRW, Howel D, Barwick DD. F-responses; a study of frequency, shape and amplitude characteristics in healthy control subjects. $J$ Neurol Neurosurg Psychiatry 1985;48:1159-64.

${ }^{10}$ Thomas PK, Sears TA, Gilliatt RW. The range of conduction velocity in normal motor nerve fibres to the small muscles of the hand and foot. J Neurol Neurosurg Psychiatry 1959;22:175-81.

"Mulder DW, Lambert EH, Bastron JA, Sprague RG. The neuropathies associated with diabetes mellitus. Neurology (Minneap) 1961;11:275-84.

12 Trojaborg W. Motor nerve conduction velocities in normal subjects with particular reference to the conduction in proximal and distal segments of median and ulnar nerve. Electroencephalogr Clin Neurophysiol 1964;17:314-21. 
${ }^{13}$ Lang AH, Bjorkovist ES. Die hervenleitzesch windigkeit peripheral nerves beernffussend $F$ konstitytionelle faktotes. $E E G-E M G$ 1971;21:162-70.

${ }^{14}$ La Fratta CW, Smith OH. A study of the relationship of motor nerve conduction velocity in the adult to age, sex and handedness. Arch Phys Med Rehab 1964; 45:407-12.

${ }^{15}$ Chatterjee DS, Barwick DD, Petrie A. Exploratory electromyography in the study of vibration-induced white-finger in rock drillers. Br J Indust Med 1982.

${ }^{16}$ Campbell MJ, McComas AJ, Petito F. Physiological changes in aging muscles. $J$ Neurol Neurosurg Psychiatry 1973;36:174-82.

17 Dawson GD, Merton PA. 'Recurrent' discharges from motor neurones. Abstract. 20th International Congress of Physiology, Bruxelles. 1956:221-2.

18 Thorne J. Central responses to electrical activation of the peripheral nerves supplying the intrinsic hand muscles. J Neurol Neurosurg Psychiatry 1965;28: 482-95.

${ }^{19}$ McLeod JG, Wray SH. An experimental study of the F wave in the baboon. $J$ Neurol Neurosurg Psychiatry 1966;29: 196-200.

${ }^{20}$ Trontelj JV. A study of the F-responses by single fibre electromyography. In: Desmedt JE, ed. New Developments in Electromyography and Clinical Neurophysiology. Basel: Karger, 1973:318-22.

${ }^{21}$ Young RR, Shahani BT. Clinical value and limitations of F-wave determination. Muscle Nerve 1978;1:248-50.

22 Fullerton PM, Gilliat RW. Axon reflexes in human nerve fibres. J Neurol Neurosurg Psychiatry 1965;28:1-11.

${ }^{23}$ Barron SA, Kolb D. F-responses in amytrophic lateral schlerosis. AAEE Abstracts Muscle Nerve. 1982 September: 556.

${ }^{24}$ Potts FA, Shahani BT, Young RP. F response amplitude and its relationship to the motor unit. Neurology $(N Y)$ 1982;31:86.

${ }^{25}$ McComas AJ, Fawcett PRW, Campbell MJ, Sica REP. Electrophysiological estimation of the number of motor unit within a human muscle. J Neurol Neurosurg Psychiatry 1971;34:121-31.

${ }^{26}$ Sica REP, McComas AJ, Upton ARM, Longmire D. Motor unit estimations in small muscles of the hand. $J$ Neurol Psychiatry 1974;37:55-67.

${ }^{27}$ Stalberg E, Fawcett PRW. Macro EMG in healthy subjects of different ages. J Neurol Neurosurg Psychiatry 1982;45:870-8.

${ }^{28}$ Yates SK, Brown WF. Characteristics of the F response: a single motor unit study. J Neurol Neurosurg Psychiatry 1979;42:161-70.

${ }^{29}$ Kadrie HA, Brown WF. Neuromuscular transmission in single human motor units. J Neurol Neurosurg Psychiatry 1978;41:193-204.

${ }^{30}$ Kimura J, Yanagisawa H, Yamada T, Mitsudome A, Sasaki $H$, Kimura $A$. Is the $F$ wave elicited in a select group of motorneurons? Muscle Nerve 1984;7:392-9.

${ }^{31}$ Eisen A, Odusote K. Amplitude of the F-wave: a potential means of documenting spasticity. Neurol (Minneap) $1979 ; 29: 1306-9$.

${ }^{32}$ Hong CZ, Joynt RL, Lin JC, Lufty S, Causin P, Meltzer RJ. Axillary F-loop latency of ulnar nerve in normal young adults. Arch Phys Med Rehabil 1981;62:565-9.

${ }^{33}$ Fisher MA. F-response latency-duration correlations: an argument for the orderly antidromic activation of motor neurones. Muscle Nerve 1980;3:437-8. 